\title{
PEMERIKSAAN STROKE RISKOMETER PADA POPULASI RISIKO TINGGI DALAM RANGKA HARI STROKE SEDUNIA
}

\author{
Stroke Riskometer Examination in High Risk Populations for World Stroke Day
}

\section{Ilsa Hunaifi ${ }^{* 1}$, Herpan Syafii Harahap ${ }^{1}$, M. Galvan Sahidu ${ }^{1}$, Dewi Suryani ${ }^{2}$, Ni Nyoman Ayu Susilowati ${ }^{3}$, Asri Buana Citra Dewi ${ }^{4}$}

\author{
${ }^{1}$ Bagian Neurologi Fakultas Kedokteran Universitas Mataram, ${ }^{2}$ Bagian Mikrobiologi \\ Fakultas Kedokteran Universitas Mataram, ${ }^{3}$ Bagian Neurologi RSUD Patut Patuh Padju \\ Lombok Barat, ${ }^{4}$ Rumah Sakit Siloam, Mataram
}

Universitas Mataram, Jalan Pendidikan Nomor 37, Kota Mataram, Provinsi NTB

Alamat korespondensi: ilsahunaifi@unram.ac.id

(Tanggal Submission: 28 July 2021, Tanggal Accepted : 19 Agustus 2021)

\begin{abstract}
Kata Kunci : $\quad$ Abstrak :
Stroke, Stroke Stroke merupakan penyebab kematian dan kecacatan utama di Indonesia. World Riskometer Stroke Organization (WSO) melaporkan 1 dari 4 orang di Dunia pernah mengalami gejala stroke. Untuk menurunkan angka kejadian stroke pada tingkat individu dan populasi, saat ini dikembangkan aplikasi berupa Stroke Riskometer untuk menghitung risiko stroke pada seseorang. Kegiatan pengabdian kepada masyarakat ini bertujuan untuk memberikan edukasi dan pencegahan stroke di masa yang akan datang. Kegiatan pengabdian kepada masyarakat ini dilakukan dengan menganalisa faktor risiko pada peserta yang mengikuti acara hari Stroke Sedunia di Rumah Sakit Siloam Mataram dengan menggunakan Stroke Riskometer. Peserta yang mempunyai risiko tinggi terjadinya stroke dilakukan edukasi untuk mencari strategi mencegah stroke di masa yang akan datang. Peserta sebanyak 20 orang. Pada peserta laki-laki mempuntai Body Mass Index (BMI) lebih tinggi dibandingkan perempuan (26.2 vs 23.84 ) serta tekanan darah sistolik leboh tinggi dibandingkan perempuan (140.71 vs 127.15$)$. Rata-rata risiko stroke dalam 5 tahun ke depan sebesar $4.3 \%$ pada laki-laki dan $2.5 \%$ pada perempuan dan risiko stroke dalam 10 tahun ke depan sebesar $9.1 \%$ pada lakilaki dan $4.03 \%$ pada perempuan. Pemeriksaan Stroke Riskometer yang dilakukan pada populasi yang mempunyai faktor risiko dapat memperkirakan risiko stroke sehingga dapat segera dilakukan pencegahan maupun pengobatan. Perlu dilakukan pemeriksaan risiko stroke tersebut dalam skala yang lebih luas.
\end{abstract}

Panduan sitasi / Citation guidance (APPA $7^{\text {th }}$ edition) :

Hunaifi, I., Harahap, H. S., Sahidu, M. G., Suryani, D., Susilowati, N. Y. A., \& Dewi, A. B. C. (2021). Pemeriksaan Stroke Riskometer Pada Populasi Risiko Tinggi Dalam Rangka Hari Stroke Sedunia. Abdi Insani, 8 (2), 193-197. http://doi.org/10.29303/abdiinsani.v8i2.407 


\section{PENDAHULUAN}

Stroke merupakan penyebab kecacatan dan kematian utama di Indonesia. Berdasarkan Riset Kesehatan Dasar 2018 Departemen Kesehatan Republik Indonesia, prevalensi stroke meningkat dari $7 \%$ menjadi 10.9\% dengan prevalensi tertinggi pada kelompok usia 55-64 tahun (Depkes RI, 2018). Data penelitian INTERSTROKE pada 22 negara menunjukkan bahwa $80 \%$ stroke merupakan jenis stroke sumbatan dan $20 \%$ stroke perdarahan (Donkor, 2018). Faktor risiko stroke diklasifikasikan menjadi dua yakni dapat dimodifikasi dan tidak bisa dimodifikasi. Faktor risiko yang dapat dimodifikasi antara lain hipertensi, Diabetes Melitus (DM), kadar cholesterol yang tinggi, atrial fibrilasi, gangguan jantung, merokok, obesitas, gaya hidup yang kurang sehat sedangkan faktor risiko yang tidak dapat dimodifikasi yakni usia dan jenis kelamin (O'Donnel et al., 2010). Laporan dari World Stroke Organization (WSO) menunjukkan 13 juta penduduk di dunia mengalami stroke dan 5.5 juta kematian dan 1 dari 4 orang berusia lebih dari 25 tahun pernah mengalami gejala stroke (WSO, 2021).

Pencegahan stroke merupakan faktor yang sangat penting dan memegang peranan utama untuk mencegah kecacatan dan kematian. Pencegahan secara garis besar dapat dilaksanakan dengan metode pendekatan komunitas dan pendekatan individual yang mempunyai risiko tinggi. Pencegahan tersebut dapat dilakukan pada populasi yang mempunyai hipertensi, DM, dyslipidemia, gangguan jantung dan gangguan irama jantung. Prediksi terjadi stroke dilakukan dengan menggunakan Framingham Stroke Risk Skore (FSRS). Namun seiring dengan kemajuan teknologi, penggunaan smartphone (ponsel pintar) yang sudah menyebar diseluruh dunia dimana saat ini hampir 1,4 miliar penduduk bumi menggunakan ponsel pintar maka dikembangkan aplikasi Stroke Riskometer (Parmar et al., 2015). Aplikasi ini dikembangkan oleh AUT Enterprise yang dapat mengetahui risiko stroke dalam 5 sampai 10 tahun kedepan (SFNZ, 2021).

Hari Stroke Sedunia diperingati setiap tanggal 29 Oktober. Sebagai bentuk partisipasi dalam pencegahan perlu dilakukannya pemeriksaan Stroke Riskometer pada orang dengan risiko tinggi. Hasil pemeriksaan Stroke Riskometer dapat digunakan sebagai upaya dalam pencegahan untuk menurunkan prevalensi stroke di masyarakat. Berdasarkan uraian tentang latar belakang permasalahan, maka kegiatan pengabdian kepada masyarakat ini bertujuan untuk menghitung Stroke Riskometer pada individu risiko tinggi. Kegiatan ini diharapkan bermanfaat untuk pencegahan stroke di masa yang akan datang.

\section{METODE KEGIATAN}

Dalam rangka pencegahan dan peningkatan kewaspadaan terhadap stroke, peserta terlebih dahulu diberikan edukasi dengan metode penyuluhan menggunakan power point. Edukasi tersebut berisi materi tentang stroke, tanda dan gejala stroke, apa yang harus dilakukan bila terkena stroke dan bagaimana pola hidup sehat untuk mencegah stroke. Setelah itu peserta dilakukan berbagai pemeriksaan untuk menghitung risiko terjadinya stroke dalam beberapa tahun kedepan dengan menggunakan aplikasi Stroke Riskometer.

Pemeriksaan risiko stroke dilakukan dengan melakukan menggunakan aplikasi Stroke Riskometer yang diunduh dalam play strore. Sebelum dilakukan pemeriksaan dengan menggunakan aplikasi tersebut, peserta dilakukan pengecekan data identitas berupa usia, jenis kelamin kemudian dilakukan pemeriksaan tinggi badan, berat badan, tekanan darah, pemeriksaan gula darah, pemeriksaan rekam jantung dan pemeriksaan tes fungsi kognitif dengan menggunakan MMSE (Mini Mental State Examination). 


\section{HASIL DAN PEMBAHASAN}

Edukasi diikuti oleh 20 orang peserta dari berbagai kalangan dan usia di Kota Mataram. Kegiatan dilaksanakan di RS Siloam Mataram Jalan Majapahit no 10 Mataram pada tanggal 29 Oktober 2019. Peserta terdiri dari 13 orang perempuan dan 7 orang laki-laki. Pada peserta laki-laki usia termuda 29 tahun dan tertua berusia 71 tahun, sedangkan pada perempuan usia termuda 32 tahun dan tertua berusia 65 tahun.

Kegiatan dalam rangka hari stroke sedunia ini dilaksanakan dalam 3 sesi. Sesi pertama berupa edukasi, sesi kedua tanya jawab dan sesi ketiga pemeriksaan Stroke Riskometer. Edukasi dilakukan dengan metode penyuluhan terdiri dari materi tentang stroke, tanda dan gejala stroke, apa yang harus dilakukan bila terkena stroke dan bagaimana pola hidup sehat untuk mencegah stroke.

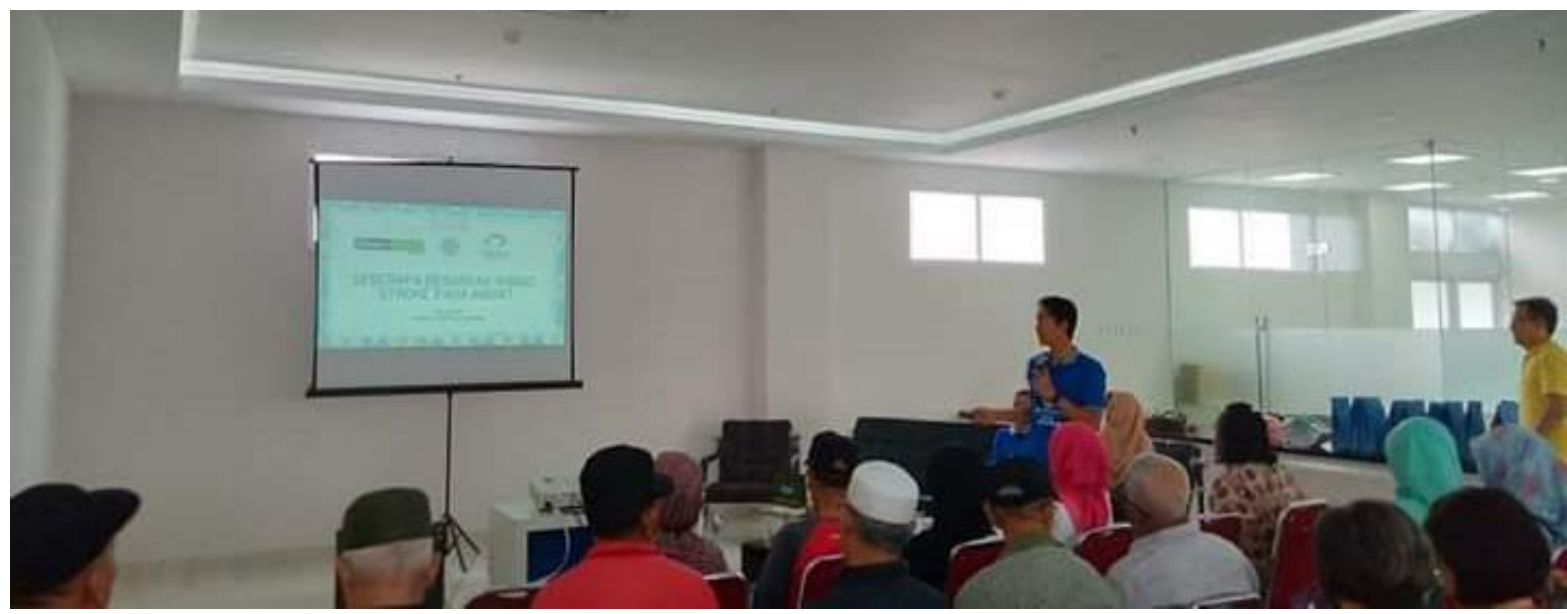

Gambar 1. Edukasi Stroke dan Pencegahannya

Pemeriksaan risiko terjadinya stroke dengan aplikasi Stroke Riskometer dibatasi untuk 20 orang dikarenakan sumber daya baik pemeriksa maupun alat yang terbatas. Adapun hasil pemeriksaan dalam perhitungan Stroke Riskometer tersaji dalam tabel 1. Pada peserta tersebut didapatkan faktor risiko stroke seperti DM, hipertensi, pernah terkena serangan stroke sebelumnya dan jarang beraktivitas fisik.

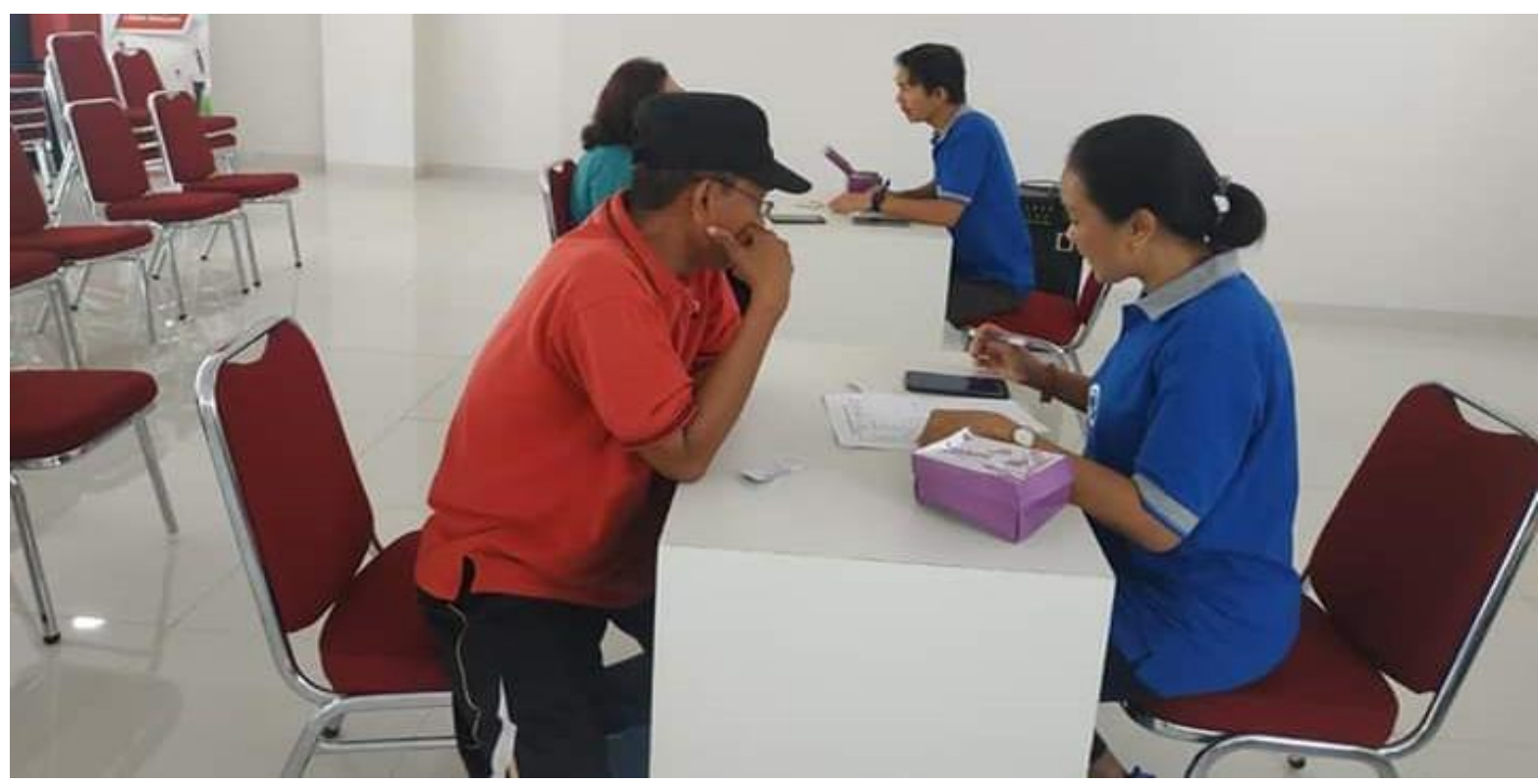

Gambar 2. Pemeriksaan Stroke Riskometer 
Tabel 1. Profil Peserta Pemeriksaan Stroke Riskometer

\begin{tabular}{lll}
\hline \multicolumn{1}{c}{ Item } & $\begin{array}{c}\text { Laki-Laki } \\
\text { (Rerata) }\end{array}$ & $\begin{array}{c}\text { Perempuan } \\
\text { (Rerata) }\end{array}$ \\
\hline Usia (tahun) & 56.57 & 49.08 \\
Tinggi Badan (cm) & 164.29 & 153.38 \\
Berat Badan (Kg) & 70.86 & 56.88 \\
BMI & 26.2 & 23.84 \\
Tekanan Darah systole (mmHg) & 140.71 & 127.15 \\
Tekanan Darah diastole (mmHg) & 81.71 & 80.23 \\
Gula darah sewaktu (mg/dl) & 123.29 & 111.08 \\
Rekam Jantung & Normal & Normal \\
Skor MMSE (Mini Mental State Examination) & 28.29 & 28.31 \\
Risiko Stroke 5 tahun & 4.3 & 2.5 \\
Risiko Stroke 10 tahun & 9.1 & 4.03
\end{tabular}

Berdasarkan data pada tabel 1 tersebut menunjukkan bahwa usia pada peserta laki-laki lebih tinggi atau lebih tua dibandingkan pada perempuan. Usia merupakan faktor risiko yang tidak dapat dimodifikasi dimana terbanyak kejadian stroke di Indonesia pada usia 55-64 tahun (Depkes RI, 2018). Selain itu peserta laki-laki rata-rata memiliki berat badan lebih (overweight) dan beberapa peserta mengalami obesitas dan tekanan darah sistolik lebih tinggi dibandingkan dengan peserta perempuan. Darah tinggi dan obesitas merupakan faktor risiko yang dapat diubah. Obesitas meningkatkan risiko terjadinya DM, hipertensi dan mempercepat terbentuknya plak aterosklerosis sehingga menimbulkan stroke (Kernan et al., 2013). Pemberian obat darah tinggi yang rutin dapat menurunkan risiko stroke berulang dan Transient Ischaemic Attack (TIA) (Wajngarten \& Silva, 2019). Selain itu olah raga atau aktivitas fisik yang rutin menurunkan risiko penyakit kardiovaskuler termasuk stroke. Gaya hidup yang sehat dapat menurunkan risiko stroke sebanyak $80 \%$ dibandingkan dengan individu yang tidak menerapkan pola hidup sehat (Howard \& McDonnell, 2015).

Risiko stroke pada individu dapat dihitung dengan menggunakan Stroke Riskometer. Berdasarkan tabel 1 menunjukkan bawa risiko stroke dalam 5 dan 10 tahun kedepan pada peserta yang berjenis kelamin laki-laki lebih tinggi 2 kali lipat dibandingkan perempuan. Data pada Riset Kesehatan Dasar Departemen Kesehatan Republik Indonesia menunjukkan bahwa stroke banyak terjadi pada laki-laki dibandingkan pada perempuan (Depkes RI, 2018). Data WHO menunjukkan bahwa laki-laki lebih banyak terkena stroke dibandingkan perempuan (Truelsen et al., 2000). Parmar et al., (2015), melaporkan bahwa Stroke Riskometer mempunyai sensitivitas yang menyerupai Framingham Stroke Risk Score sebesar $>80 \%$ pada populasi laki-laki dan perempuan dalam memperkirakan risiko stroke dalam 5 dan 10 tahun kedepan namun memiliki spesifisitas antara 44-46 $\%$ pada laki-laki dan perempuan.dalam 5 dan 10 tahun kedepan (Parmar et al., 2015).

\section{KESIMPULAN DAN SARAN}

Pemeriksaan dan perhitungan Stroke Riskometer pada populasi risiko tinggi digunakan untuk memperkirakan kejadian stroke di masa yang akan datang. Intervensi terhadap faktor risiko serta modifikasi gaya hidup dapat segera dilakukan untuk mencegah stroke. Saran perlu dilaksanakan 
pemeriksaan Stroke Riskometer dengan cakupan yang lebih luas serta melibatkan pemegang kebijakan Kesehatan sehingga angka kejadian stroke di Indonesia dapat diturunkan.

\section{UCAPAN TERIMA KASIH}

Ucapan terima kasih disampaikan kepada seluruh team pengabdian masyarakat, Perhimpulan Spesialis Saraf Seluruh Indonesia (Perdossi) Cabang Mataram dan Direktur RS Siloam Mataram yang memberikan fasilitas ruangan penyuluhan, tenaga Kesehatan, pemeriksaan gula darah dan EKG

\section{DAFTAR PUSTAKA}

$\begin{array}{llllll}\text { Depkes } & \text { RI. } & \text { (2018). Hasil Utama }\end{array}$ https://kesmas.kemkes.go.id/assets/upload/dir_519d41d8cd98f00/files/Hasilriskesdas-2018_1274.pdf

Donkor, E. S. (2018). Donkor ES. (2018). Stroke in the 21th Century: A Snapshot of The Burden, Epidemiology, and Quality of Life. Stroke Research and Treatment, 1-10. https://doi.org/10.1155/2018/3238165

Howard, V. J., \& McDonnell, M. N. (2015). Physical Activity in Primary Stroke Prevention Just Do it! Stroke, 46(1), 1735-1739. https://doi.org/10.1161/STROKEAHA.115.006317

Kernan, W. N., Inzucchi, S. E., Sawan, C., Macko, R. F., \& Furie, K. L. (2013). Obesity A Stubbornly Obvious Targer for Stroke Prevention. Stroke, 44(1), 278-286. https://doi.org/10.1161/STROKEAHA.111.639922

O’Donnel, M. J., Xavier, D., Liu, L., Zhang, H., Chin, S. L., \& Rao-Melacini, P. (2010). Risk Factors for ISchaemic and Intracerebral Haemorrhagic Stroke in 22 Countries (the INTERSTROKE Study): a case-control study. Lancet, 112-123. https://doi.org/10.1016/S01406736(10)60834-3

Parmar, P., Krishnamurthi, R., Ikram, M. A., Hofman, A., Mirza, S. A., \& Varakin, Y. (2015). The Stroke RiskometerTm App : Validation of Data Collection tool and stroke risk predictor. International Journal of Stroke, 10(1), 231-244. https://doi.org/10.1111/ijs.12411

SFNZ (Stroke Foundation New Zealand). (2021). Stroke Riskometer. Stroke Foundation New Zealand. https://www.stroke.org.nz/stroke-riskometer

Truelsen, T., Begg, S., \& Mathers, C. (2000). The Global Burden of Cerebrovascular Disease. World Health Organization. https://www.who.int/healthinfo/statistics/bod_cerebrovasculardiseasestroke.pdf.

Wajngarten, M., \& Silva, G. S. (2019). Hypertension and Stroke : Update on Treatment. European Cardiology Review, 14(2), 111-116. https://doi.org/10.15420/ecr.2019.11.1

WSO (World Stroke Organization). (2021). Learn About Stroke. World Stroke Organization. https://www.world-stroke.org/world-stroke-day-campaign/why-stroke-matters/learnabout-stroke 